\title{
Excess mortality and undertreatment in elderly lung cancer patients: treatment nihilism in the modern era?
}

\author{
Jonathan Pham ${ }^{1}$, Matthew Conron ${ }^{2}$, Gavin Wright (10 ${ }^{3,4}$, Paul Mitchell ${ }^{5}$, \\ David Ball 6,7 , Jennifer Philip ${ }^{8,9}$, Margaret Brand ${ }^{10}$, John Zalcberg ${ }^{10}$ and \\ Rob G. Stirling ${ }^{1,11}$
}

Affiliations: 'Dept of Respiratory Medicine, The Alfred Hospital, Melbourne, Australia. ${ }^{2}$ Dept of Respiratory Medicine, St Vincent's Hospital, Melbourne, Australia. ${ }^{3}$ Victorian Comprehensive Cancer Centre, Melbourne, Australia. ${ }^{4}$ Dept of Surgery, University of Melbourne, Melbourne, Australia. ${ }^{5}$ Olivia Newton-John Cancer Wellness and Research Centre, Melbourne, Australia. ${ }^{6}$ Division of Radiation Oncology, Peter MacCallum Cancer Centre, Melbourne, Australia. ${ }^{7}$ The Sir Peter MacCallum Dept of Oncology, The University of Melbourne, Parkville, Australia. ${ }^{8}$ Dept of Palliative Care, St Vincent's Hospital, Melbourne, Australia. ${ }^{9}$ Dept of Medicine, University of Melbourne, Melbourne, Australia. ${ }^{10}$ Dept of Epidemiology and Preventive Medicine, Monash University, Melbourne, Australia. ${ }^{11}$ Dept of Medicine, Monash University, Melbourne, Australia.

Correspondence: Rob G. Stirling, Respiratory Medicine, Alfred Hospital, Commercial Rd, Melbourne 3004, Australia. E-mail: r.stirlinglaalfred.org.au

ABSTRACT Treatment of elderly patients with lung cancer is significantly hindered by concerns about treatment tolerability, toxicity and limited clinical trial data in the elderly; potentially giving rise to treatment nihilism amongst clinicians. This study aims to describe survival in elderly patients with lung cancer and explore potential causes for excess mortality.

Patients diagnosed with lung cancer in the Victorian Lung Cancer Registry between 2011-2018 were analysed $(n=3481)$. Patients were age-categorised and compared using Cox-regression modelling to determine mortality risk, after adjusting for confounding. Probability of being offered cancer treatments was also determined, further stratified by disease stage.

The eldest patients ( $\geqslant 80$ years old) had significantly shorter median survival compared with younger age groups ( $<60$ years: 2.0 years; $60-69$ years: 1.5 years; $70-79$ years: 1.6 years; $\geqslant 80$ years: 1.0 years; $p<0.001$ ). Amongst those diagnosed with stage 1 or 2 lung cancer, there was no significant difference in adjustedmortality between age groups. However, in those diagnosed with stage 3 or 4 disease, the eldest patients had an increased adjusted-mortality risk of $28 \%$ compared with patients younger than 60 years old $(\mathrm{p}=0.005)$, associated with markedly reduced probability of cancer treatment, after controlling for sex, performance status, comorbidities and histology type (OR 0.24 , compared with $<60$ years old strata; $\mathrm{p}<0.001$ ).

Compared to younger patients, older patients with advanced-stage lung cancer have a disproportionately higher risk of mortality and lower likelihood of receiving cancer treatments, even when performance status and comorbidity are equivalent. These healthcare inequities could be indicative of widespread treatment nihilism towards elderly patients.

@ERSpublications

Treatment strongly determines lung cancer survival, yet nihilism may threaten treatment provision and survival outcomes. Older patients in this cohort had reduced multidisciplinary presentation, less treatment (OR 0.24$)$ and $28 \%$ increased mortality risk. https://bit.ly/2ZGotj0

Cite this article as: Pham J, Conron M, Wright G, et al. Excess mortality and undertreatment in elderly lung cancer patients: treatment nihilism in the modern era? ERJ Open Res 2021; 7: 00393 2020 [https://doi.org/10.1183/23120541.00393-2020].

This article has supplementary material available from openres.ersjournals.com

Received: 25 May 2020 | Accepted: 15 Feb 2021

Copyright $\odot$ The authors 2021. This version is distributed under the terms of the Creative Commons Attribution NonCommercial Licence 4.0. For commercial reproduction rights and permissions contact permissions@ersnet.org 


\section{Introduction}

Lung cancer is the most common and lethal cancer worldwide with an estimated 1.76 million deaths in 2018 [1,2]. Age is a significant risk factor for lung cancer mortality, with peak mortality occurring in patients aged $\geqslant 80$ years [3]. Furthermore, the prevalence of cancer in the elderly is increasing, likely as a result of population growth, increased longevity and advances in medical care [4].

Survival following diagnosis may be impacted by patient, disease and treatment-related factors. Many patient-related factors, including age, remain implacable; and with increasing age, there is likely to be increasing burden of comorbidity and frailty. Advancing age is strongly associated with poorer performance status, an important predictor of poor prognosis $[5,6]$. Therefore, careful elicitation of such patient-related factors is an important precedent in identifying treatment suitability.

Access to treatment for the elderly has the potential to be significantly limited by concerns regarding treatment tolerability, potential toxicity, uncertainty about treatment efficacy and nihilism. Estimation of treatment tolerability and toxicity in the elderly is challenging [7]. Both renal and liver function are age dependent $[8,9]$ and pharmacokinetics and pharmacodynamics differ in the elderly compared with their younger counterparts [10]. Age-related renal impairment may therefore be associated with significant risk of toxicity from traditional chemotherapy [11], and indeed in the over 70 years population, rates of severe treatment toxicity in advanced non-small cell lung cancer have been observed to be doubled following radiotherapy and trebled following chemotherapy or combination chemotherapy and radiotherapy [12].

Concerns around the efficacy of treatment in the elderly may relate to an absence of evidence of efficacy of such treatments in the elderly. Underrepresentation of older patient groups in conventional chemotherapy trials has been long recognised [13] and similar underrepresentation is observed for novel therapeutics, including immunotherapies [14]. Such concerns are likely to lead to significant diagnostic and therapeutic nihilism causing clinicians to fail to investigate and potentially withhold required treatments due to anticipated regret [15].

A consideration of age is therefore a critical factor in the confirmation of appropriateness in the selection of established, novel and emerging treatments in managing elderly patients with lung cancer. Our study aims to describe treatment patterns in elderly patients, determine differences in mortality and identify risk factors for excess mortality.

\section{Methods}

\section{Patients}

We analysed all patients diagnosed with lung cancer in the Victorian Lung Cancer Registry (VLCR) between 2011 and 2017. The VLCR is a clinical quality registry, collecting information about diagnosis, management and outcomes of individuals newly diagnosed with lung cancer in Victoria (Australia) and providing risk-adjusted benchmarking of quality indicators to participating institutions [16]. The VLCR currently captures over $80 \%$ of newly diagnosed lung cancers from the state of Victoria from 43 participating hospitals, representative of the majority of public and private hospitals. This study was approved by the Human Research Ethics Committee at Monash University (MUHREC: 22368).

\section{Variables}

Variables analysed included: age, sex, ethnicity, comorbidities, comorbid malignancy (excluding skin), performance status, histology, date of diagnosis, presentation at multi-disciplinary meeting, cancer treatment, palliative care referral, survival and date of death. Ethnicity was coded based on the Australian Standard Classification of Cultural and Ethnic Groups (ASCCEG), 2019 [17]. Histology was derived from tumour morphology using the third edition of the International Classification of Diseases for Oncology (ICD-O-3) [18]. Cancer treatment was defined as surgery, chemotherapy, radiotherapy, immunotherapy or targeted therapy (e.g. tyrosine kinase inhibitors). Comorbidities assessed by the VLCR are: diabetes, renal insufficiency, myocardial infarction, respiratory disease and neoplastic comorbidity. These illnesses are defined by specific criteria (see supplemental table 1). Patients with missing data in any of these fields were excluded from analysis.

\section{Statistical analysis}

Age at diagnosis was categorised into four groups: $<60$ years; 60 to 69 years; 70 to 79 years, $\geqslant 80$ years. Relationships between age group and baseline characteristics were assessed using chi-square tests. All-cause mortality was compared between age groups using Kaplan-Meier estimates. We used Cox-regression modelling to estimate and compare mortality risk between age groups, after adjusting for confounders (sex, ethnicity, performance status, number of comorbidities, comorbid malignancy, disease stage, histology, cancer treatment). 
We also assessed outcomes stratified by disease stage (early versus advanced stage) and compared the probability of receipt of cancer treatment for each age group using logistic regression, adjusting for confounders (sex, number of comorbidities, comorbid malignancy, performance status and histology). We compared the frequency of patients in each age group who were discussed at multidisciplinary meetings. A sensitivity analysis of the primary outcomes was performed amongst patient excluded from analysis due to incomplete data and compared to the analytical sample. Analyses were performed using STATA version 13.

\section{Results}

A total of 3481 patients were analysed. The distribution of age in the study population was: $<60$ years: 679 (19.5\%); 60-69 years: 1082 (31.1\%); 70-79 years: 1191 (34.2\%), $\geqslant 80$ years: 529 (15.2\%). The patient, disease and treatment characteristics of each age group is shown in table 1 . Of note, the eldest patient group ( $\geqslant 80$ years old) tended to have more males, Europeans (and fewer South-East Asians), patients with poorer performance status $(\mathrm{p}<0.001$ for each). Not unexpectedly, older age strata tended to have more comorbidities than younger strata $(\mathrm{p}<0.001)$ and the eldest patient group had more patients in early compared to advanced stage disease compared with the youngest patient group $(p=0.012)$. Considerably fewer patients in the eldest patient group received cancer treatment for lung cancer $(<60$ years: $93.2 \%$; 60-69 years: $89.0 \%$; $70-79$ years: $86.6 \%$; $\geqslant 80$ years: $71.8 \%$; $p<0.001)$. A small minority of patients declined any cancer treatment, which increased with age strata (<60 years: 16 (2.4\%); 60-69 years: 39 (3.6\%); $70-79$ years: $44(3.7 \%), \geqslant 80$ years: $40(7.6 \%)$. The eldest patient group also had the highest rate of referral to palliative care (44\%) compared to younger age groups ( $<60$ years: $27.9 \%$; $60-69$ years: $26.1 \%$; 70-79 years: 29.8\%; $\mathrm{p}<0.001)$.

The probability of survival after being diagnosed with lung cancer, stratified by age group, is shown in the Kaplan-Meier curve (figure 1). Median overall survival was progressively shorter with increasing age, ( $<60$ years: 2.0 years; $60-69$ years: 1.5 years; $70-79$ years: 1.6 years; $\geqslant 80$ years: 1.0 years; $\mathrm{p}<0.001$ ).

Univariate and multivariate analyses were performed to estimate the mortality risk of various patient characteristics, see table 2. Concordant with Kaplan-Meier estimates, the mortality risk tended to increase with advancing age. After adjusting for other risk factors, multivariate analysis demonstrated that only the eldest age group had an increased risk of all-cause mortality (HR death $\geqslant 80$ years old: 1.31 compared to $<60$ years old age group; $\mathrm{p}=0.001$ ). As expected, performance status and disease stage were the strongest predictors of mortality. Males, compared with females, also had a 16\% increase risk of all-cause mortality, after adjusting for other risk factors. North/Western European, North/Eastern Asian and South/Eastern Asian ethnicity was associated with a significant protective effect on mortality compared to other ethnicities (table 2), possibly related to treatment-responsive genetic mutations. The number of comorbidities did not significantly predict mortality. Small cell lung cancer and not-otherwise-specified (NOS) lung cancer histology were associated with higher mortality risk compared to other histological subtypes.

In advanced disease, only $63.8 \%$ of patients aged $\geqslant 80$ years, were presented for discussion at a multi-disciplinary meeting (table 3 ). This was markedly fewer compared to those in other age groups ( $<60$ years: $77.0 \%$; 60-69 years: $69.5 \%$; $70-79$ years: $71.6 \%$; $p<0.001$ ). There was no statistical difference between age groups presented as a multi-disciplinary meeting in early stage disease.

Crude data demonstrated increased mortality in elderly patients; however, for patients with stage 1 or 2 disease at diagnosis there was no significant difference in adjusted-mortality between age groups (see table 4). In those diagnosed with stage 3 or 4 disease, however, the eldest patients had an increased adjusted-mortality risk of $28 \%$ compared with patients aged $<60$ years $(p=0.005)$. In early stage disease, there was no difference between age groups in the probability of being provided cancer treatments, after controlling for confounders. However, in late-stage disease, the adjusted probability of being provided cancer treatment significantly and progressively fell with increasing age; the eldest age group having an odds ratio of a quarter of those aged $<60$ years (OR: 0.24 ; $\mathrm{p}<0.001$ ).

Sensitivity analysis was performed to evaluate potential bias by patients excluded from primary analysis due to incomplete data $(\mathrm{n}=4199 ; 54.7 \%)$, finding a poorer median overall survival in the excluded group (sample: 11.9 months versus excluded: 7.4 months, $\mathrm{p}=0.011$ ) and a lower rate of cancer treatment compared to elderly patients in the analysed sample (sample: $71.8 \%$ versus excluded: $50.3 \%$; $<<0.001$ ). We also found a disproportionately higher number of elderly patients that did not have histo-cytological confirmation compared to other age strata (<60 years: $1.6 \%$; $60-69$ years: $3.2 \% ; 70-79$ years: $4.7 \%$; $\geqslant 80$ years: $14.6 \% ; \mathrm{p}<0.001)$.

\section{Discussion}

The central finding from our study is that elderly patients diagnosed with advanced lung cancer have a $28 \%$ excess mortality risk, driven by under-treatment of patients who may have otherwise had a favourable 


\section{TABLE 1 Baseline characteristics by age group}

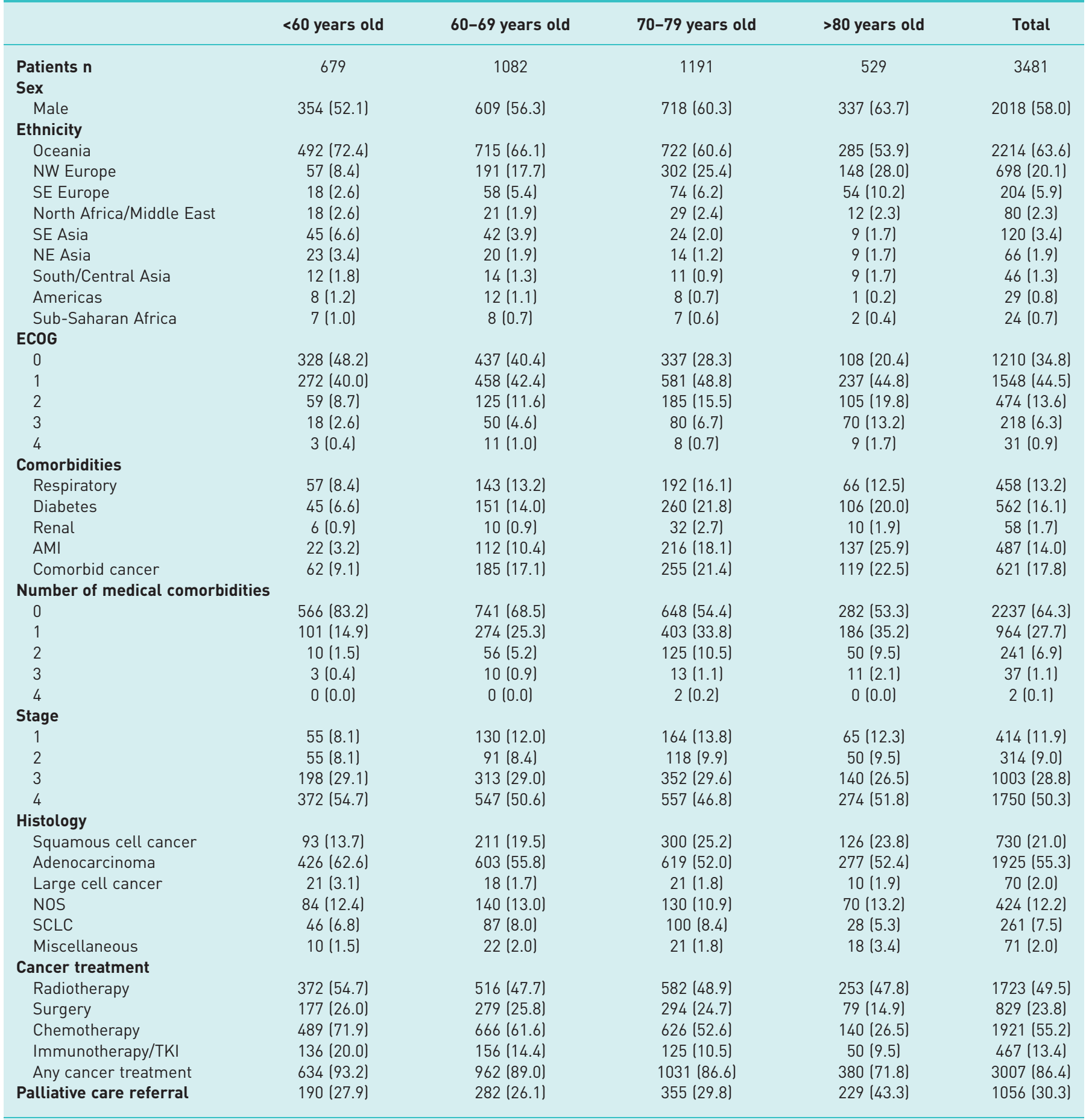

Data are presented as n (\%), unless otherwise stated. ECOG: Eastern Cooperative Oncology Group; AMI: acute myocardial infarction; NOS: not otherwise specified; SCLC: small cell lung cancer; TKI: tyrosine kinase inhibitors (targeted therapy).

response. This association persists even after controlling for known factors that influence treatment tolerability and response: sex, comorbidities, performance status and histology [5, 19-21]. Studies from lung cancer registries in other Western countries, including the USA and Germany, have also demonstrated under-treatment of elderly patients with lung cancer $[22,23]$. In addition to replicating these findings in an Australian setting, our study identifies high-risk groups within the elderly population 


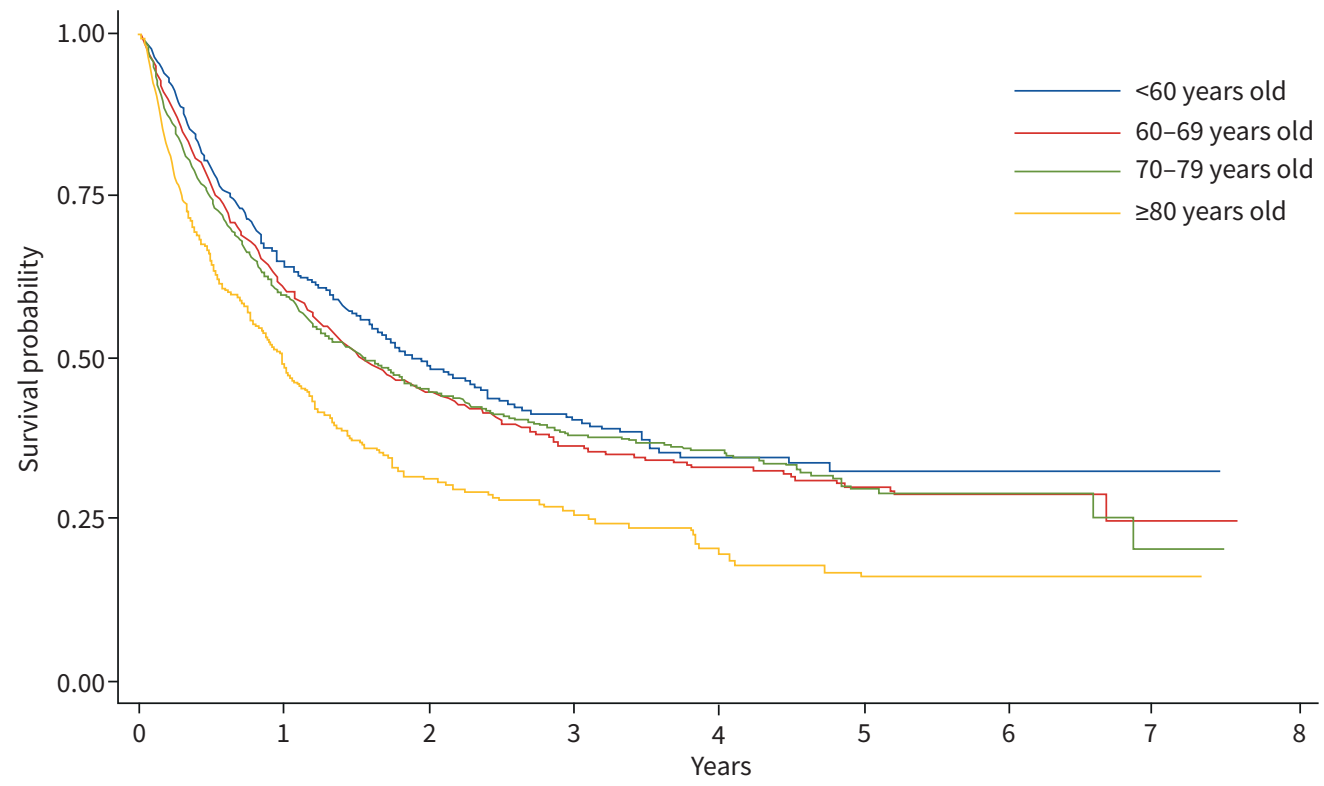

FIGURE 1 Kaplan-Meier estimate of the probability of survival among patients diagnosed with lung cancer, stratified by age.

who can be targeted for future intervention: those with advanced-stage lung cancer and those not discussed at multidisciplinary meetings.

One potential explanation for less cancer treatment being prescribed for elderly patients is treatment nihilism. Clinicians, family members or patients themselves may perceive treatment at advanced age as futile, especially in the context of incurable disease and significant risk of treatment toxicity. A survey of clinicians involved in care of elderly patients with lung cancer showed that stage was a major factor in determining management [24].

However, treatment of lung cancer in the elderly is not futile, even despite late-stage disease. There are emerging data that modified treatment regimens designed specifically for the elderly can offer better tolerated side-effect profiles whilst still maintaining a survival benefit. SIGEL et al. [25] demonstrated, in a non-randomised study, that radiotherapy alone, compared with best supportive care, improved survival in elderly patients with stage III non-small cell lung cancer. However, benefits in mortality were offset by considerable toxicity leading to pneumonitis and oesophagitis requiring hospitalisation. Conversely, KHOR et al. [26] reported a study on tolerability of curative intent radiotherapy in a population aged $>85$ years, finding that $79 \%$ of patients completed the prescribed treatment without poor treatment tolerability, and 95\% of patients completed all treatment, with poor performance status and age predicting tolerability and survival.

Careful patient selection for surgical resection of early stage disease in the elderly suggests that resection can also be performed with short and long-term outcomes consistent with younger cohorts, where sub-lobar resection appears to provide better short-term survival and lobectomy better long-term survival $[27,28]$.

Tyrosine kinase inhibitors (TKI) may also provide a useful adjunct or alternative to chemotherapy. Compared head to head with single-agent chemotherapy, gefitinib had equivalent survival benefit with good tolerability in the elderly [29]. Taken together, these findings appear to provide an evolving body of clinical research supporting the delivery of evidence-based treatment of elderly patients with lung cancer. However, our sensitivity analysis shows that there was a disproportionate number of elderly patients who did not have histo-pathological confirmation; far greater than any other age strata. This could potentially limit therapeutic options in this population, particularly with regard to targeted therapies, such as TKIs, and adversely affect survival. This is not an uncommon issue in real-life clinical practice; a study of non-small cell lung cancer patients in the National Lung Cancer Audit in England (NLCA) also found disproportionately lower odds of histo-cytological confirmation and anticancer treatment in elderly patients [30]. In the modern era of expanded and well-tolerated therapies for lung cancer, histopathological confirmation should be encouraged for all patients, especially those of advanced age. 


\begin{tabular}{|c|c|c|c|c|}
\hline & \multicolumn{2}{|c|}{ Univariate analysis } & \multicolumn{2}{|c|}{ Multivariate analysis } \\
\hline & $\operatorname{HR}(95 \% \mathrm{CI})$ & p-value & $\operatorname{HR}(95 \% \mathrm{CI})$ & p-value \\
\hline \multicolumn{5}{|l|}{ Sex } \\
\hline Female & ref & & ref & \\
\hline Male & $1.20(1.09-1.31)$ & $<0.001$ & $1.16(1.06-1.28)$ & 0.002 \\
\hline \multicolumn{5}{|l|}{ Age group years } \\
\hline$<60$ & ref & & ref & \\
\hline $60-69$ & $1.13(0.99-1.29)$ & 0.079 & $1.09(0.95-1.25)$ & 0.238 \\
\hline $70-79$ & $1.15(1.01-1.31)$ & 0.041 & $1.07(0.93-1.23)$ & 0.324 \\
\hline$>80$ & $1.66(1.43-1.93)$ & $<0.001$ & $1.31(1.11-1.54)$ & 0.001 \\
\hline \multicolumn{5}{|l|}{ Ethnicity } \\
\hline Oceania & ref & & ref & \\
\hline NW Europe & $0.94(0.84-1.05)$ & 0.282 & $0.82(0.73-0.93)$ & 0.001 \\
\hline SE Europe & $1.11(0.92-1.34)$ & 0.277 & $1.08(0.89-1.31)$ & 0.456 \\
\hline North Africa/Middle East & $1.02(0.75-1.39)$ & 0.884 & $1.08(0.79-1.47)$ & 0.636 \\
\hline SE Asia & $0.69(0.52-0.92)$ & 0.012 & $0.7(0.52-0.93)$ & 0.014 \\
\hline NE Asia & $0.50(0.33-0.77)$ & 0.001 & $0.46(0.30-0.70)$ & $<0.001$ \\
\hline South/Central Asia & $0.71(0.45-1.10)$ & 0.122 & $0.68(0.44-1.07)$ & 0.094 \\
\hline Americas & $0.72(0.42-1.25)$ & 0.245 & $0.71(0.41-1.22)$ & 0.215 \\
\hline Sub-Saharan Africa & $0.45(0.22-0.90)$ & 0.024 & $0.59(0.29-1.19)$ & 0.141 \\
\hline \multicolumn{5}{|l|}{ ECOG } \\
\hline 0 & ref & & ref & \\
\hline 1 & $1.67(1.49-1.87)$ & $<0.001$ & $1.44(1.29-1.62)$ & $<0.001$ \\
\hline 2 & $2.91(2.54-3.35)$ & $<0.001$ & $2.12(1.83-2.45)$ & $<0.001$ \\
\hline 3 & $4.27(3.60-5.06)$ & $<0.001$ & $2.81(2.34-3.37)$ & $<0.001$ \\
\hline 4 & $15.85(10.92-23.00)$ & $<0.001$ & $9.83(6.71-14.41)$ & $<0.001$ \\
\hline \multicolumn{5}{|l|}{ Comorbidities $\mathrm{n}$} \\
\hline 0 & ref & & ref & \\
\hline 1 & $1.12(1.01-1.24)$ & 0.025 & $1.1(0.99-1.22)$ & 0.086 \\
\hline 2 & $1.15(0.96-1.37)$ & 0.123 & $1.03(0.86-1.24)$ & 0.739 \\
\hline 3 & $1.29(0.85-1.94)$ & 0.233 & $1.01(0.66-1.55)$ & 0.967 \\
\hline 4 & $0.66(0.09-4.73)$ & 0.683 & $1.64(0.23-11.76)$ & 0.621 \\
\hline \multicolumn{5}{|l|}{ Comorbid malignancy } \\
\hline Not present & ref & & ref & \\
\hline Present & $1.00(0.89-1.13)$ & 0.965 & $1.01(0.90-1.14)$ & 0.843 \\
\hline \multicolumn{5}{|l|}{ Stage } \\
\hline 1 & ref & & ref & \\
\hline 2 & $2.14(1.60-2.85)$ & $<0.001$ & $1.93(1.44-2.58)$ & $<0.001$ \\
\hline 3 & $2.95(2.32-3.76)$ & $<0.001$ & $2.59(2.03-3.31)$ & $<0.001$ \\
\hline 4 & $6.62(5.25-8.35)$ & $<0.001$ & $5.6(4.42-7.09)$ & $<0.001$ \\
\hline \multicolumn{5}{|l|}{ Histology } \\
\hline Squamous cell carcinoma & ref & & ref & \\
\hline Adenocarcinoma & $0.94(0.83-1.05)$ & 0.284 & $0.91(0.80-1.03)$ & 0.117 \\
\hline Large cell carcinoma & $1.12(0.81-1.55)$ & 0.501 & $1.05(0.76-1.46)$ & 0.777 \\
\hline NOS & $1.46(1.25-1.70)$ & $<0.001$ & $1.19(1.01-1.39)$ & 0.009 \\
\hline SCLC & $1.50(1.26-1.79)$ & $<0.001$ & $1.27(1.06-1.52)$ & 0.037 \\
\hline Miscellaneous & $1.38(1.01-1.88)$ & 0.040 & $0.94(0.68-1.30)$ & 0.706 \\
\hline \multicolumn{5}{|l|}{ Any cancer treatment } \\
\hline No & ref & & ref & \\
\hline Yes & $0.41(0.36-0.46)$ & $<0.001$ & $0.57(0.50-0.64)$ & $<0.001$ \\
\hline
\end{tabular}

ECOG: Eastern Cooperative Oncology Group; NOS: not otherwise specified; SCLC: small cell lung cancer; HR: hazard ratio for mortality; ref: reference group. Bold indicates significance.

Despite this, there remains gross under-representation of elderly patients in cancer research [13]. An analysis of phase III lung cancer trials in systemic therapy showed that a third of all trials excluded elderly patients and that the mean age of trial participants was nearly a decade younger than the median age of all newly diagnosed lung cancer patients in population-based cancer studies [13, 31]. These findings are confirmed in meta-analyses of novel treatments including immunotherapy trials [14].

Self-reported questionnaire data suggests that the vast majority of clinicians view comorbidities and treatment toxicity as the most challenging issues encountered when providing care for elderly patients with 
TABLE 3 Patients presented at multidisciplinary meeting, stratified by stage and age

\begin{tabular}{|c|c|c|c|c|c|c|}
\hline \multirow[b]{2}{*}{ Age group } & \multicolumn{2}{|c|}{ Stage 1 and 2 disease } & \multicolumn{2}{|c|}{ Stage 3 and 4 disease } & \multicolumn{2}{|c|}{ All stages } \\
\hline & n (\%) & p-value & n $(\%)$ & p-value & n $(\%)$ & p-value \\
\hline$<60$ years & 100 (90.9) & 0.07 & $439(77.0)$ & $<0.001$ & 539 (79.3) & $<0.001$ \\
\hline $60-69$ years & $182(82.4)$ & & 598 (69.5) & & 780 (72.2) & \\
\hline 70-79 years & $227(80.5)$ & & $651(71.6)$ & & 878 (73.7) & \\
\hline$>80$ years & $91(79.1)$ & & $266(64.3)$ & & $357(67.1)$ & \\
\hline All age groups & $600(82.4)$ & & $1952(70.9)$ & & 2552 (73.3) & \\
\hline
\end{tabular}

lung cancer [24]. Unfortunately, there are few decision aids available to help clinicians predict treatment success or failure in elderly patients. Comprehensive geriatric assessment (CGA) is a clinical tool that has been validated to predict mortality and treatment toxicities in elderly patients with cancer by assessing a wide range of health measures [32]. A study by MAIONE et al. [33] demonstrated a strong association between CGA score and all-cause mortality in non-small cell lung cancer in elderly individuals. Furthermore, specific domains of the CGA strongly predicted toxicity to chemotherapy: poor mobility, cognitive impairment, malnutrition, social difficulties and polypharmacy [33]. However, despite its clear clinical utility in geriatric oncology, CGA is infrequently used in clinical practice due its timely and resource-intensive nature.

Managing elderly patients with lung malignancy can be challenging in clinical practice. It requires synthesising multiple factors: determining how research is applicable to the individual patient, predicting which treatment regime will provide the optimal quality of life, and ensuring patient autonomy in decision making. Given these complexities, a multi-disciplinary-based approach, which brings together a range of clinical and research expertise, is likely to be highly beneficial. However, our study demonstrates that increasing age was generally associated with lower rates of presentation at a multidisciplinary meeting. Therefore, our central finding of low probability of cancer treatment in the elderly could be, at least in part, due to low levels of multidisciplinary discussion.

Choice of treatment and patient autonomy is important when considering management of elderly patients. In our study, elderly patients appear to have more than double the frequency of declining treatment in our study which could contribute to increased mortality. However, the overall number of study participants who declined treatment was 139 , equating to just $4.0 \%$ of our study cohort $(n=3481)$. As such, the contribution of declining treatment to increased mortality in the elderly is likely to be minimal.

One limitation of our study was the narrow spectrum of illnesses used to determine comorbid health in the VLCR. It is possible that clinicians evaluated an individual's fitness for treatment based on health parameters beyond these. However, some studies have demonstrated that comorbidity is poorly predictive

TABLE 4 Probability of cancer treatment and death, stratified by stage and age

\begin{tabular}{|c|c|c|c|c|}
\hline \multirow[t]{2}{*}{ Age group } & \multicolumn{2}{|c|}{ Cancer treatment } & \multicolumn{2}{|c|}{ Death } \\
\hline & Odds ratio $\#(95 \% \mathrm{CI})$ & p-value & Hazard ratio" $(95 \% \mathrm{CI})$ & p-value \\
\hline$<60$ years & ref & & ref & \\
\hline 60-69 years & $1.25(0.29-5.44)$ & 0.769 & $0.84(0.50-1.40)$ & 0.497 \\
\hline $70-79$ years & $1.61(0.37-6.95)$ & 0.522 & $0.97(0.59-1.58)$ & 0.887 \\
\hline$>80$ years & $0.54(0.12-2.41)$ & 0.423 & $1.29(0.75-2.21)$ & 0.354 \\
\hline $60-69$ years & $0.61(0.38-0.97)$ & 0.036 & $1.12(0.97-1.29)$ & 0.119 \\
\hline $70-79$ years & $0.46(0.29-0.73)$ & 0.001 & $1.05(0.91-1.22)$ & 0.485 \\
\hline$>80$ years & $0.24(0.15-0.38)$ & $<0.001$ & $1.28(1.08-1.51)$ & 0.005 \\
\hline
\end{tabular}


of mortality in elderly patients and/or those with advanced stage disease [34-37] although some studies have unsurprisingly demonstrated poorer survival in those with severe comorbidity [38]. However, the primary objective of our study was not to analyse the effect of comorbidity on cancer mortality; we used the number of comorbidities merely as a surrogate measure to adjust for confounding in our statistical models, a technique previously used in research literature [39]. It is also possible that the natural history of death in elderly patients in the general population contributes to mortality of elderly patients with lung cancer. Unfortunately, our dataset was composed entirely of patients with lung cancer, and thus we were unable to adjust our statistical models for risk of mortality in elderly patients in the general population. However, it has been shown from other studies that mortality between elderly individuals with and without lung cancer is vastly different. VENUTA et al. [40] noted that life expectancy of patients aged 80 years in the USA is 9.1 years compared with just 14 months for elderly patients with early stage untreated lung cancer. The authors concluded that life limitations in this age group are purely related to cancer.

Another limitation of our study was the large number of patients (54.7\%) from the VLCR who had missing data and were subsequently excluded from analysis, which may introduce selection bias. Sensitivity analysis of these patients, however, demonstrates even worse survival and under-treatment of the elderly compared to our study subjects. Therefore, our findings are likely to be an under-representation of the true extent of healthcare inequality in the elderly.

\section{Conclusion}

Compared with younger patients, older patients diagnosed with advanced-stage lung cancer have a disproportionately higher risk of mortality. This is associated with reduced delivery of cancer treatment to older patients, even when performance status and comorbidities are equivalent to younger patients. Possible health care targets for intervention, at an institutional level are: 1) improving culture and reducing stigma and treatment nihilism towards elderly patients; 2) using validated clinical tools to enhance confirmation of suitability of elderly patients for cancer treatment; 3) mandating a multidisciplinary-based approach for all patients, regardless of age or disease stage; and 4) establishing a clinical governance framework that ensures equity in lung cancer care. This study suggests that equitable delivery of lung cancer treatment could lead to improved survival in the elderly.

Conflict of interest: J. Pham has nothing to disclose. M. Conron has nothing to disclose. G. Wright has nothing to disclose. P. Mitchell has nothing to disclose. D. Ball reports lectures fees from AstraZeneca outside the submitted work. J. Philip has nothing to disclose. M. Brand has nothing to disclose. J. Zalcberg reports support for data collection from AstraZeneca, BMS, MSD and Abbvie outside the submitted work. R.G. Stirling has nothing to disclose.

\section{References}

1 International Agency for Research on Cancer. International Agency for Cancer Research Global Cancer Observatory Lung Globocan 2018. Geneva, World Health Organization, 2018.

2 Bray F, Ferlay J, Soerjomataram I, et al. Global cancer statistics 2018: GLOBOCAN estimates of incidence and mortality worldwide for 36 cancers in 185 countries. CA Cancer J Clin 2018; 68: 394-424.

3 AIHW. AIHW \& Cancer Australia 2011. Lung cancer in Australia: an overview. Cancer series no 64 Cat no CAN 58. Canberra, AIHW, 2011.

4 Parry C, Kent EE, Mariotto AB, et al. Cancer survivors: a booming population. Cancer Epidemiol Biomarkers Prev 2011; 20: 1996-2005.

5 Divo MJ, Martinez CH, Mannino DM. Ageing and the epidemiology of multimorbidity. Eur Respir J 2014; 44 $1055-1068$.

6 Dujon C, Azarian R, Azarian V, et al. [Lung cancer in the elderly: performance status and/or geriatric indices?]. Rev Mal Respir 2006; 234 Pt 1: 307-318.

7 Kim J, Hurria A. Determining chemotherapy tolerance in older patients with cancer. J Natl Compr Canc Netw 2013; 11: 1494-1502.

8 Weinstein JR, Anderson S. The aging kidney: physiological changes. Adv Chronic Kidney Dis 2010; 17: 302-307.

9 Cieslak KP, Baur O, Verheij J, et al. Liver function declines with increased age. HPB 2016; 18: 691-696.

10 Wildiers H, Highley MS, de Bruijn EA, et al. Pharmacology of anticancer drugs in the elderly population. Clin Pharmacokinet 2003; 42: 1213-1242.

11 Mathe C, Bohacs A, Duffek L, et al. Cisplatin nephrotoxicity aggravated by cardiovascular disease and diabetes in lung cancer patients. Eur Respir J 2011; 37: 888-894.

12 Kale MS, Mhango G, Gomez JE, et al. Treatment toxicity in elderly patients with advanced non-small cell lung cancer. Am J Clin Oncol 2017; 40: 470-476.

13 Jennens RR, Giles GG, Fox RM. Increasing underrepresentation of elderly patients with advanced colorectal or non-small-cell lung cancer in chemotherapy trials. Int Med J 2006; 36: 216-220.

14 Khan M, Lin J, Liao G, et al. Comparative analysis of immune checkpoint inhibitors and chemotherapy in the treatment of advanced non-small cell lung cancer: a meta-analysis of randomized controlled trials. Medicine 2018; 97: e11936.

15 Mamede S, Schmidt HG. The twin traps of overtreatment and therapeutic nihilism in clinical practice. Med Educ 2014; 48: 34-43. 

lung cancer care through the use of a disease quality registry. Lung 2014; 192: 749-758. Australian Bureau of Statistics. 2019. Australian Standard Classification of Cultural and Ethnic Groups (ASCCEG) https://www.abs.gov.au/ausstats/abs@.nsf/mf/1249.0.

18 Percy C, Fritz A, Jack A, et al. International Classification of Diseases for Oncology (ICD-O-3). Geneva, World Health Organisation, 2000.

19 Brechot JM, Chevret S, Charpentier MC, et al. Blood vessel and lymphatic vessel invasion in resected nonsmall cell lung carcinoma. Correlation with TNM stage and disease free and overall survival. Cancer 1996; 78: 2111-2118.

20 Colinet B, Jacot W, Bertrand D, et al. A new simplified comorbidity score as a prognostic factor in non-small-cel lung cancer patients: description and comparison with the Charlson's index. Br J Cancer 2005; 93: 1098-1105.

21 Charloux A, Rossignol M, Purohit A, et al. International differences in epidemiology of lung adenocarcinoma. Lung Cancer 1997; 16: 133-143

22 Cassidy RJ, Zhang X, Switchenko JM, et al. Health care disparities among octogenarians and nonagenarians with stage III lung cancer. Cancer 2018; 124: 775-784.

23 Walter J, Tufman A, Holle R, et al. "Age matters"-German claims data indicate disparities in lung cancer care between elderly and young patients. PLOS ONE 2019; 14: e0217434.

24 Ayyappan S, Gonzalez C, Yarlagadda R, et al. Lung cancer in the very elderly: incidence, presentation, and diagnostic decision-making. A retrospective analysis at a teaching community hospital. J Community Hosp Intern Med Perspect 2011; 1: 7313.

25 Sigel K, Lurslurchachai L, Bonomi M, et al. Effectiveness of radiation therapy alone for elderly patients with unresected stage III non-small cell lung cancer. Lung Cancer 2013; 82: 266-270.

26 Khor RC, Bressel M, Tedesco J, et al. Tolerability and outcomes of curative radiotherapy in patients aged 85 or more years. Med J Aust 2015; 202: 153-155.

27 Vazirani J, Moraes J, Barnett S, et al. Outcomes following resection of non-small cell lung cancer in octogenarians ANZ J Surg 2018; 88: 1322-1327.

28 Shirvani SM, Jiang J, Chang JY, et al. Lobectomy, sublobar resection, and stereotactic ablative radiotherapy for early-stage non-small cell lung cancers in the elderly. JAMA Surg 2014; 149: 1244-1253.

29 Morikawa N, Minegishi Y, Inoue A, et al. First-line gefitinib for elderly patients with advanced NSCLC harboring EGFR mutations. A combined analysis of North-East Japan Study Group studies. Expert Opin Pharmacother 2015; 16: 465-472.

30 Beckett P, Callister M, Tata LJ, et al. Clinical management of older people with non-small cell lung cancer in England. Thorax 2012; 67: 836-839.

31 Sacher AG, Le LW, Leighl NB, et al. Elderly patients with advanced NSCLC in phase III clinical trials: are the elderly excluded from practice-changing trials in advanced NSCLC? J Thorac Oncol 2013; 8: 366-368.

32 Ramjaun A, Nassif MO, Krotneva S, et al. Improved targeting of cancer care for older patients: a systematic review of the utility of comprehensive geriatric assessment. J Geriatr Oncol 2013; 4: 271-281.

33 Maione P, Perrone F, Gallo C, et al. Pretreatment quality of life and functional status assessment significantly predict survival of elderly patients with advanced non-small-cell lung cancer receiving chemotherapy: a prognostic analysis of the multicenter Italian lung cancer in the elderly study. J Clin Oncol 2005; 23: 6865-6872.

34 Ball D, Thursfield V, Irving L, et al. Evaluation of the Simplified Comorbidity Score (Colinet) as a prognostic indicator for patients with lung cancer: a cancer registry study. Lung Cancer 2013; 82: 358-361.

35 Jorgensen TL, Hallas J, Friis S, et al. Comorbidity in elderly cancer patients in relation to overall and cancer-specific mortality. Br J Cancer 2012; 106: 1353-1360.

36 Janssen-Heijnen ML, Smulders S, Lemmens VE, et al. Effect of comorbidity on the treatment and prognosis of elderly patients with non-small cell lung cancer. Thorax 2004; 59: 602-607.

37 Girones R, Torregrosa D, Gomez-Codina J, et al. Prognostic impact of comorbidity in elderly lung cancer patients: use and comparison of two scores. Lung Cancer 2011; 72: 108-113.

38 Luchtenborg M, Jakobsen E, Krasnik M, et al. The effect of comorbidity on stage-specific survival in resected non-small cell lung cancer patients. Eur J Cancer 2012; 48: 3386-3395.

39 Blanco JA, Toste IS, Alvarez RF, et al. Age, comorbidity, treatment decision and prognosis in lung cancer. Age Ageing 2008; 37: 715-718.

40 Venuta F, Diso D, Onorati I, et al. Lung cancer in elderly patients. J Thorac Dis 2016; 8: Suppl. 11, S908-S914. 